\title{
Sphenoid Sinuses Pneumatization and Association with the Protrusion of Surrounding Neurovascular Structures amongst Beninese
}

\author{
Djivèdé Akanni ${ }^{1,2^{*}}$, Canicius Ovidio de Souza ${ }^{3,4}$, Kofi-Mensa Savi de Tovè1,2, Kouassi Paul N'zi ${ }^{5,6}$, \\ Patricia Yèkpè̀ $^{3,4}$, Olivier Biaou ${ }^{3,4}$, Vicentia Boco ${ }^{3,4}$ \\ ${ }^{1}$ Faculty of Medicine, University of Parakou, Parakou, Benin \\ ${ }^{2}$ Department of Radiology, University Teaching Hospital of Borgou Department, Parakou, Benin \\ ${ }^{3}$ Faculty of Health Sciences, University of Abomey Calavi, Cotonou, Benin \\ ${ }^{4}$ Department of Radiology, National and University Teaching Hospital Hubert Koutoukou Maga, Cotonou, Benin \\ ${ }^{5}$ Faculty of Medicine, University Félix Houphouet-Boigny, Abidjan, Cote d'Ivoire \\ ${ }^{6}$ Institut of Cardiology, Abidjan, Cote d'Ivoire \\ Email: *djivakanni@yahoo.fr
}

How to cite this paper: Akanni, D., de Souza, C.O., de Tovè, K.-M.S., N'zi, K.P., Yèkpè, P., Biaou, O. and Boco, V. (2018) Sphenoid Sinuses Pneumatization and Association with the Protrusion of Surrounding Neurovascular Structures amongst Beninese. Open Journal of Radiology, 8, 209-216. https://doi.org/10.4236/ojrad.2018.84024

Received: September 21, 2018 Accepted: November 5, 2018

Published: November 8, 2018

Copyright $\odot 2018$ by authors and Scientific Research Publishing Inc. This work is licensed under the Creative Commons Attribution International License (CC BY 4.0).

http://creativecommons.org/licenses/by/4.0/

\section{(c) (i) Open Access}

\begin{abstract}
Goal: The aim of this work is to study the relationship between the pneumatization of the adjacent structures of sphenoid sinuses and the protrusion of the neurovascular structures in the sinuses. Methods: A review of $225 \mathrm{CT}$ scans skull was done for subjects aged at least 16 years old from November 1st to December 31st 2017. The pneumatization of adjacent structures of sphenoid sinuses and its relation with the protrusion of neurovascular structures surround the sinuses have been investigated. We used Fischer Exact test for comparison. The $\mathrm{p}$ value $<0.05$ was expressed as significant. Results: Statistically significant associations were found between anterior clinoid process bilateral pneumatization and bilateral protrusion of carotid canal $(\mathrm{p}<0.05)$ and of optic canal $(\mathrm{p}<0.001)$. There were also, statistically significant correlations between bilateral pterygoid process pneumatization and bilateral protrusion of carotid canal and of optic canal $(\mathrm{p}<0.001)$; and between pterygoid process bilateral pneumatization and bilateral protrusion of maxillary and vidian nerves $(\mathrm{p}<0.001)$. An association was also found between bilateral pneumatization of great wings and bilateral protrusion of maxillary nerves $(\mathrm{p}$ $<0.001)$ and of vidian nerves $(\mathrm{p}<0.05)$. Conclusion: Compared to the literature, the prevalence of pneumatization of the adjacent structures of sphenoid sinuses was lower on Beninese than Caucasian and Asian. But there were the same correlations with the protrusion of neurovascular structures. In case of endonasal surgery of the sphenoid sinuses, surgeon should be aware of
\end{abstract}


the high possibility the injury of optic nerves and internal carotid artery.

\section{Keywords}

Sphenoid, Pneumatization, Neurovascular Structures, Association, Benin

\section{Introduction}

The variability of the anatomy of the sphenoid sinuses is well documented [1] [2] [3]. Sphenoid sinuses are probably the most variably pneumatized structures of the skull [1] [2] [3]. According to anatomic description, the sphenoid sinuses growth will reach their full extension on adolescence [4] [5]. The pneumatization of sphenoid sinuses is variable and ranges from minimal to extensive [4] [5] and it may occasionally extend into the different parts of the sphenoid bone, such as ACP (Anterior Clinoid Processes), lesser and the great wings, and PP (Pterygoid Processes). Sphenoid sinuses are surrounded by vital neurovascular structures, such as the internal carotid artery, opticnerves, maxillary and vidian nerves. The description of these anatomic variants in different populations gives useful information [6] [7] [8]. A previous work has studied the anatomic variants of sphenoidal sinuses and adjacent structures amongst Beninese [9]. However, few articles studied the relationship between pneumatization of adjacent structures of sphenoid sinuses and protrusion of neurovascular structures in black Africans [6]. The current work aimed to study the relationship between bilateral pneumatization of adjacent structures of sphenoid sinuses and bilateral protrusion of surrounding neurovascular structures at the National and University Teaching Hospital Hubert Koutoukou Maga of Cotonou (CNHU-HKM/Cotonou).

\section{Methods}

A retrospective descriptive and analytical study was conducted. Computed Tomography (CT scan) images of the skull of Beninese subjects without obvious anomalies in paranasal sinuses were collected in the Radiology Department of National and Teaching Hospital Hubert Koutoukou Maga of Cotonou from 1st November to 31st December 2017. Included subjects aged at least 16 years. Exhaustive recruitment of all patients was done during the period of study. The subjects were scanned on EMOTION SIEMENS 16-slices CT. CT-scan were systematically reviewed in the bone window and soft tissue window after multiplanar reconstruction. The thickness of the reconstructed image slice was $1 \mathrm{~mm}$.

We studied the pneumatization of anterior clinoid processes, of pterygoid processes, of lesser and great wings; the protrusion of carotid canals and of optic canals, the protrusion of maxillary and vidian nerves. The anatomic images were already described in a previous work [9].

Protrusion was defined as the presence of at least one third of the canal circumference into the sinus cavity. Protrusion of the vidian nerves was defined as the presence of air density around the nerves [9]. 
Data collection was done using a survey form prepared for the circumstance. Data analyses were done by using Epi info software version 3.5.4. A descriptive analysis of the variables was done. Mean age and standard deviation were calculated. For qualitative variables, frequencies and proportions were calculated. The Comparisons of multiple variances were applied with using Fisher Exact test. The $\mathrm{p}$-value $<0.05$ was expressed as significant. The risk ratio (RR) was used to measure the association between sphenoid sinuses pneumatization and the protrusion of surrounding neurovascular structures. RR gives an indication of the "strength of association". RR is an intuitive way to compare the risks for two groups. Simply divide the cumulative incidence in exposed group by the cumulative incidence in the unexposed group:

$$
\text { Risk Ratio }=\frac{C l e}{C l u}
$$

where Cle is the cumulative incidence in the "exposed" group and Clu the cumulative incidence in the "unexposed" group.

These associations were tested only when both bilateral pneumatization of structures adjacent to sphenoid sinuses and bilateral protrusion of neurovascular structures were present simultaneously.

The ethical commission of CNHU-HKM has given his agreement and the data were used in absolute confidentiality.

\section{Results}

\subsection{Description of Anatomic Variants}

225 Skull CT-scans were collected. 224 had two sphenoid sinuses and one had a single sphenoid sinus.

Their age ranged from 16 to 86 years with mean age of 48.8 years \pm 17.2 . There was male predominance $58.7 \%$ with a sex-ratio of 1.42 .

Table 1 represents the detailed data about bony anatomic variations. Pneumatization of lesser and great wings of the sphenoid were observed in $3.3 \%$ and

Table 1. The prevalence of bony anatomic variations, CNHU-HKM, 2017.

\begin{tabular}{ccccc}
\hline Anatomic variations & Bilateral & Right side & Left side & Total \\
\hline Pneumatizaton & $\mathrm{n}(\%)$ & $\mathrm{n}(\%)$ & $\mathrm{n}(\%)$ & $\mathrm{n}(\%)$ \\
\hline Lesser wing & $12(2.7)$ & $1(0.2)$ & $2(0.4)$ & $15(3.3)$ \\
Great wing & $14(3.1)$ & $3(0.7)$ & $4(0.9)$ & $21(4.6)$ \\
Anterior Clinoid Process & $16(3.6)$ & $9(2.0)$ & $7(1.5)$ & $32(7.1)$ \\
Pterygoid Process & $28(6.2)$ & - & $5(1.1)$ & $33(7.3)$ \\
Protrusion & & & & \\
Carotid Canal & $208(46.3)$ & $4(0.9)$ & $5(1.1)$ & $217(48.3)$ \\
Optic Canal & $44(9.8)$ & $7(1.5)$ & $8(1.8)$ & $59(13.1)$ \\
Maxillary Nerve & $72(16)$ & $3(0.7)$ & $6(1.3)$ & $81(18)$ \\
Vidian Nerve & $19(8.4)$ & 0 & $2(0.4)$ & $21(9.5)$ \\
\hline
\end{tabular}


4.6\% of patients respectively. Pneumatization of Anterior Clinoid Processes (ACP), and of Pterygoid Processes (PP); were found in $7.1 \%$ and $7.3 \%$ of patients, respectively. Protrusion of Carotid Canal (CC), and Optic Canal (OC) were found in $48.3 \%$ and $13.1 \%$ of patients, respectively. The Protrusion of Maxillary and Vidian nerves were found in $18 \%$ and $9.5 \%$ of the cases, respectively.

\subsection{Sphenoid Sinuses Pneumatization and Association with the Protrusion of Surrounding Neurovascular Structures}

Many protrusion of surrounding neurovascular structures were associated with pneumatization of adjacent structures of sphenoid sinuses.

Statistically significant correlations were found between: ACP bilateral pneumatization and bilateral protrusion of carotid canal $(\mathrm{p}<0.05)$, and optic canal ( $\mathrm{p}$ $<0.001$ ), Table 2 . There were also, statistically significant association between bilateral PP pneumatization and bilateral protrusion of CC and of OC ( $\mathrm{p}<$ 0.001), Table 2. An association was also found between bilateral PP pneumatization and bilateral protrusion of maxillary and vidian nerves $(\mathrm{p}<0.001)$, Table 3 . Likewise statistically significant correlations were observed between bilateral pneumatization of great wings and bilateral protrusion of maxillary nerves ( $\mathrm{p}<$ $0.001)$ and bilateral protrusion of vidian nerves $(\mathrm{p}<0.05)$, Table 3.

Table 2. Relationship between ACP pneumatization and protrusion of CC and of OC and between PP pneumatization and protrusion of CC and of OC, CNHU-HKM, 2017.

\begin{tabular}{ccccccc}
\hline & \multicolumn{3}{c}{ Carotid Canal } & \multicolumn{3}{c}{ Optic Canal } \\
\hline & ${ }^{*} \mathrm{RR}$ & ${ }^{* *} \mathrm{IC}$ & $\mathrm{p}$ & ${ }^{*} \mathrm{RR}$ & ${ }^{* *} \mathrm{IC}$ & $\mathrm{p}$ \\
\hline ACP Pneumatizaton & & & & & & \\
No & 1 & & & 1 & & - \\
Yes & 2.26 & $1.94-2.62$ & 0.0017 & 15.50 & $9.33-25.72$ & $<0.0001$ \\
PP Pneumatization & & & & & & \\
No & 1 & & & 1 & & - \\
Yes & 2.34 & $2.00-2.74$ & $<0.0001$ & 1.41 & $1.06-1.88$ & $<0.0001$ \\
\hline
\end{tabular}

${ }^{*} \mathrm{RR}$ : relative risk, ${ }^{* *} \mathrm{IC}$ : confidence interval.

Table 3. Relationship between PP pneumatization and protrusion of maxillary and vidian nerves and between Great wings pneumatization and protrusion of maxillary and vidian nerves, CNHU-HKM, 2017.

\begin{tabular}{ccccccc}
\hline & \multicolumn{3}{c}{ Maxillary nerve } & \multicolumn{3}{c}{ Vidian nerve } \\
\hline & ${ }^{*} \mathrm{RR}$ & ${ }^{* *} \mathrm{IC}$ & $\mathrm{p}$ & ${ }^{*} \mathrm{RR}$ & ${ }^{* *} \mathrm{IC}$ & $\mathrm{p}$ \\
\hline $\begin{array}{c}\text { PP Pneumatizaton } \\
\text { No }\end{array}$ & 1 & & & & & \\
Yes & 6.63 & $4.19-10.48$ & $<0.0001$ & 6.95 & $3.11-15.51$ & 0.0003 \\
$\begin{array}{c}\text { Great wings } \\
\text { Pneumatization }\end{array}$ & & & & & & \\
No & 1 & & & & & - \\
Yes & 7.51 & $5.35-10.54$ & $<0.0001$ & 5.84 & $2.20-15.51$ & 0.014 \\
\hline
\end{tabular}

${ }^{*} \mathrm{RR}$ : relative risk, ${ }^{* *} \mathrm{IC}$ : confidence interval. 


\section{Discussion}

The current work aimed to study the relationship between pneumatization of adjacent structures of sphenoid sinuses and protrusion of neurovascular structures on Beninese.

\subsection{Prevalence of Pneumatization of Adjacent Structures of Sphenoid Sinuses}

Pneumatization of the sphenoid can extend in all its components, like the great and lesser wings, PP, and ACP [10] [11]. These extensions of sinuses bring them in close relations to vessels and nerves of the skull base such as internal carotid artery, optic nerves, maxillary and vidian nerves. The relations of sphenoid sinuses with the structures around are close when sinusesare well pneumatized [10] [12] [13]. When this happens, the surrounding vessels and nerves are seen in sinuses cavity (protrusion) as irregularities or ridges [14].

In this study, the rate of the pneumatization of the adjacent structures of the sphenoid was lower than the rate according to the literature. In our series, pneumatization of PP was 7.3\% versus $15.5 \%$ - 43.6\% [12] [13] [14] [15], pneumatization of ACP was $7.1 \%$ versus $11 \%$ - 29\% [12] [13] [14] [15] and pneumatization of great wings was $4.6 \%$ versus $20 \%$ according to Hewaidi and Omani [16].

\subsection{Prevalence of Protrusion of Neurovascular Structures}

Prevalences of the protrusion of surrounding neurovascular structures observed in our study were comparable with the rate seen in other studies. In our series, protrusion of CC was $48.3 \%$ versus $34 \%$ - 93\%, protrusion of OC was $13.1 \%$ versus $4 \%-37.5 \%$, protrusion of vidian nerves was $9.5 \%$ versus $7.5 \%-13.3 \%$ [12] [13] [14] [15] and protrusion of maxillary nerves was $18 \%$ versus $24.3 \%$ according to Hewaidi and Omani [16].

\subsection{Associations between Pneumatization and Protrusion}

In the current study, there were statistically significant association between the pneumatization of ACP and protrusion of OC ( $<<0.001)$. Hewaidi and Omani [16], Kazkayasi et al. [17], Sirikci et al. [18], and Rahmati et al. [14] had reported the same association between ACP pneumatization and protrusion of OC. But these studies did not give the level of risk of protrusion of CO in case of ACP pneumatization. This risk was 15 times higher in our study. Therefore, in the presence of a bilateral pneumatization of ACP, it is necessary to fear a lesion of the optic nerves during an endonasal surgery.

There were also statistically significant correlations between the pneumatization of ACP and protrusion of CC ( $p<0.05)$. Protrusion of CC was found to increase as ACP pneumatization increased in three studies [13] [19] [20]. Similarly, our study showed that the pneumatization of ACP and of PP double the risk to see protrusion of CC. This findings means that an inattention in case of endonasal surgery when bilateral pneumatization of both ACP and PP exist, may result 
in injury of internal carotid artery in its intrasinusal tract. Such an injury usually leads to bad outcome.

According to our results, there were 7 times higher risk to seeprotrusion of both maxillary and vidian nerves when the PP pneumatization exist. This association between PP pneumatization and protrusion of maxillary and vidian nerves had already pointed out by Hewaidi and Omani [16], by Rahmati et al. [14] and Kazkayasi et al. [17] without give clearly the level of the association.

As Hewaidi and Omani [16], we had found a relationship between the pneumatization of great wing and the protrusion of maxillary nerves $(\mathrm{p}<0.001)$. But the correlations between pneumatization of $\mathrm{PP}$ and protrusion of $\mathrm{OC}$, and between pneumatization of great wing of sphenoid and vidian nerve were not seen in other studies.

Despite the relatively low pneumatization rate of adjacent structures within the study population, the prevalence of protrusion of neurovascular structures were consistent with that found in other studies. Correlations between the pneumatization of adjacent structures and the protrusion of neurovascular structures found in our studies have been corroborated by other studies.

\subsection{Limitation of the Study}

The retrospective characteristic of the study, the number of cases and the absence of additional readers to compare the results of the first reading are limits to this study.

\section{Conclusion}

The prevalence of pneumatization of the adjacent structures of sphenoid sinus was lower on Beninese than Caucasian or Asian population compared to literature. But there were the same correlations between the pneumatisation of the adjacent structures and the protrusion of surrounding neurovascular structures of sphenoid sinuses amongst Beninese. According to our results, the risk of blindness and hemorrhages seems to be clearly higher among the Beninese, in case of endonasal surgery of the sphenoid sinuses. Thus, the results of this study call our surgeons to more use CT scan before surgery on sphenoid sinuses.

\section{Authors' Contributions}

Akanni D conceived the study. de Souza C collected the data. Akanni D and de Souza $\mathrm{C}$ analyzed the data. Akanni drafted the manuscript. All authors approved the final version of the article.

\section{Conflicts of Interest}

The authors have no conflict of interest to declare.

\section{References}

[1] Hamid, O., El Fiky, L., Hassan, O., Kotb, A. and El Fiky, S. (2008) Anatomic Varia- 
tions of the Sphenoid Sinus and Their Impact on Trans-Sphenoid Pituitary Surgery. Skull Base, 18, 9-15. https://doi.org/10.1055/s-2007-992764

[2] Unal, B., Bademci, G., Bilgili, Y.K., Batay, F. and Avci, E. (2006) Risky Anatomic Variations of Sphenoid Sinus for Surgery. Surgical and Radiologic Anatomy, 28, 195-201. https://doi.org/10.1007/s00276-005-0073-9

[3] Wang, J., Bidari, S., Inoue, K., Yang, H. and Rhoton, A. (2010) Extensions of the Sphenoid Sinus. Neurosurgery, 66, 797-816. https://doi.org/10.1227/01.NEU.0000367619.24800.B1

[4] Casselman, J.W. (2003) The Sphenoid Bone: Anatomy. Journal of Neuroradiology, 30, 201-210.

[5] Hammer, G. and Radberg, C. (1961) The Sphenoidal Sinus An Anatomical and Roentgenologic Study with Reference to Transsphenoid Hypophysectomy. Acta Radiologica: Original Series, 56, 401-422.

[6] Fasunla, A., Ameye, S., Adebola, O., Ogbole, G., Adeleye, A. and Adekanmi, A. (2012) Anatomical Variations of Sphenoid Sinus and Nearby Neurovascular Structures Seen on Computed Tomography of Black African. COSECSA/ASEA Publication-East and Central African Journal of Surgery, 17, 57.

[7] Idowu, O.E., Balogun, B.O. and Okoli, C.A. (2009) Dimensions, Septation, and Pattern of Pneumatization of the Sphenoidal Sinus. Folia Morphologica, 68, 228-232.

[8] Kajoak, S.A., Ayad, C.E., Abdalla, E.A., Mohammed, M.N., Yousif, M.O. and Mohammed, A.M. (2013) Characterization of Sphenoid Sinuses for Sudanese Population Using Computed Tomography. Global Journal of Health Science, 6, No. 1. http://www.ccsenet.org/journal/index.php/gjhs/article/view/28959 https://doi.org/10.5539/gjhs.v6n1p135

[9] Yèkpè, P., Akanni, D., de Souza, C., Adjadohoun, S., Kiki, M., Savi de Tovè, K.M., Biaou, O. and Boco, V. (2018) Anatomic Variants of Sphenoid Sinuses and Adjacent Structures: A Study of 225 Skull CT Scans at CNHU-HKM in Benin, West Africa. Open Journal of Radiology, 8, 181-190. https://doi.org/10.4236/ojrad.2018.83021

[10] Lu, Y., Pan, J., Qi, S., Shi, J., Zhang, X. and Wu, K. (2011) Pneumatization of the Sphenoid Sinus in Chinese: The Differences from Caucasian and Its Application in the Extended Transsphenoidal Approach: Pneumatization of the Sphenoid Sinus in Chinese. Journal of Anatomy, 219, 132-142. https://doi.org/10.1111/j.1469-7580.2011.01380.x

[11] ELKammash, T.H., Enaba, M.M. and Awadalla, A.M. (2014) Variability in Sphenoid Sinus Pneumatization and Its Impact upon Reduction of Complications Following Sellar Region Surgeries. The Egyptian Journal of Radiology and Nuclear Medicine, 45, 705-714. https://doi.org/10.1016/j.ejrnm.2014.04.020

[12] Budu, V., Mogoantă, C.A., Fănuță, B. and Bulescu, I. (2013) The Anatomical Relations of the Sphenoid Sinus and Their Implications in Sphenoid Endoscopic Surgery. Romanian Journal of Morphology and Embryology, 54, 13-16.

[13] Cho, J.H., Kim, J.K., Lee, J.-G. and Yoon, J.-H. (2010) Sphenoid Sinus Pneumatization and Its Relation to Bulging of Surrounding Neurovascular Structures. Annals of Otology, Rhinology \& Laryngology, 119, 646-650. https://doi.org/10.1177/000348941011900914

[14] Rahmati, A., Ghafari, R. and AnjomShoa, M. (2016) Normal Variations of Sphenoid Sinus and the Adjacent Structures Detected in Cone Beam Computed Tomography. Journal of Dentistry, Shiraz University of Medical Sciences, 17, 32-37.

[15] Turkdogan, F.T., Turkdogan, K.A., Dogan, M. and Atalar, M.H. (2017) Assessment of Sphenoid Sinus Related Anatomic Variations with Computed Tomography. The 
Pan African Medical Journal, 27, 109.

https://doi.org/10.11604/pamj.2017.27.109.7391

[16] Hewaidi, G.H. and Omami, G.M. (2008) Anatomic Variation of Sphenoid Sinus and Related Structures in Libyan Population: CT Scan Study. Libyan Journal of Medicine, 3, 128-133. https://doi.org/10.3402/ljm.v3i3.4775

[17] Kazkayasi, M., Karadeniz, Y. and Arikan, O.K. (2005) Anatomic Variations of the Sphenoid Sinus on Computed Tomography. Rhinology, 43, 109-114.

[18] Şirikci, A., Bayazıt, Y.A., Bayram, M., Mumbuç, S., Güngör, K. and Kanlıkama, M. (2000) Variations of Sphenoid and Related Structures. European Radiology, 10, 844-848. https://doi.org/10.1007/s003300051016

[19] Lupascu, M., Comsa, G.I. and Zainea, V. (2014) Anatomical Variations of the Sphenoid Sinus-A Study of 200 Cases. ARS Medica Tomitana, 20, 57-62.

[20] Dal Secchi, M.M., Dolci, R.L.L., Teixeira, R. and Lazarini, P.R. (2018) An Analysis of Anatomic Variations of the Sphenoid Sinus and Its Relationship to the Internal Carotid Artery. International Archives of Otorhinolaryngology, 22, 161-166.

https://doi.org/10.1055/s-0037-1607336 